\title{
Pathology of Heterakis gallinarum in the ceca of naturally infected chicken (Gallus domesticus)
}

\author{
Zubeda Butt*, Shakeel Ahmed Memon and Azra Anjum Shaikh \\ Department of Zoology, University of Sindh, Jamshoro-76080, Pakistan \\ *Corresponding author's email: Sonhdinawaz_butt@yahoo.com \\ Citation \\ Zubeda Butt, Shakeel Ahmed Memon and Azra Anjum Shaikh. Pathology of Heterakis gallinarum in the ceca of \\ naturally infected chicken (Gallus domesticus). Pure and Applied Biology. Vol. 5, Issue 4, pp815-821. \\ http://dx.doi.org/10.19045/bspab.2016.50102
}

Received: $26 / 04 / 2016$

Revised: 25/07/2016

Accepted: 02/08/2016

Online First: 08/08/2016

\section{Abstract}

Present study was aimed to examine the pathology of nematode (Heterakis gallinarum) in the ceca of local chicken (Gallus domesticus). A total of 90 chickens (Gallus domesticus) were randomly purchased from different villages and local markets of District Hyderabad, Pakistan. Birds were dissected and different parts of intestine were recovered. Out of 90 birds 83 were found infected with a variety of helminth parasites. The sex wise nematode Heterakis gallinarum was collected from cecum of infested chickens. Tissues from infected ceca were fixed in Bouin's fluid for 24 hours for histopathological examinations using routine histological techniques, $6 \mu \mathrm{m}$ thick sections were stained by using principal staining procedure of hematoxylin and eosin (H\&E). The parasitic Heterakis gallinarum prevalence was $20 \%$ of infected chickens. Histopathological findings revealed sever damage of cecal architecture, necrosis of lamina propria, destruction of intestinal glands. Infected cecum was showing muscular alterations like vacuolation and tearing of muscles. Further investigations are suggested to reduce the risk factors of nematode infestation in birds which will ultimately minimize further losses.

Keywords: Chicken; Nematode parasite; Heterakis gallinarum; Pathology; Ceca

\section{Introduction}

Poultry farming is one of the most important sectors of agricultural industries throughout world providing high energy food meat \& eggs and they are considered rich energy nutritional source of proteins [1]. Poultry farming is an essential business sector play a significant role in enhancement of the social- economic status of rural communities. Annually more than 50,000 million chickens are reared for their meat [2, 3]. In developing countries like Pakistan majority of families from rural communities keep chickens flocks in free range scavenging system. Due to the free range scavenging system, the chickens are susceptible to parasitic infestations from their habitats, particularly gastrointestinal parasitic infections which results heavy financial losses. These parasitic infestations are causing severe health problems of growth, egg laying performance and mortality. Beside the viral and bacterial infection poultry birds have also been affected by parasitic infections [4, 5]. Nematodes, Trematodes, and cestodes are recognized as most important gastrointestinal helminthes in poultry sector 
and number of Protozoan and Nematode species cause severe gastrointestinal damage. The main genera include Capillaria, Heterakis and Ascaridia [6]. The high incidence of gastrointestinal infection in chicken is caused by helminth parasites. Free range chicken flocks are looking for their food in habitats which are often contaminated by various parasites, animal and human wastes. These contaminants serve as intermediate host for gastrointestinal parasites that infect chicken flocks [7-9]. The nematode Heterakis gallinarum has an extensive biological host distribution especially in birds and this has been reported in various studies from Pakistan [10-12].

Keeping in view of significant medical and socio economic importance of poultry sector, present study was carried out to evaluate the intestinal damage caused by nematode parasite Heterakis gallinarum in naturally infected chicken. So that to expand knowledge of pathogenicity and possible attention may be given towards the management of free ranges chicken.

Materials and methods

Adult free range local chickens (Gallus domesticus) were purchased from local markets and different villages of Hyderabad, Sindh, Pakistan. The obtained birds were slaughtered at parsititology laboratory, Departement of Zoology, University of Sindh, Jamshoro, Pakistan. There after birds were dissected for the collection of gastrointestinal parasites and searching of helminthes was carried out by stereoscopic microscope and magnifying glass by applying method of Dharejo [13]. The recovered parasites from the caecum of each dissected bird were kept in normal saline solution. A heated mixture of $70 \%$ ethanol and $5 \%$ glycerin was used for stretching and killing of parasites then same parasites were shifted in $70 \%$ ethanol and glycerin by $1: 1$ ratio for further process. Parasites were mounted in glycerin for identification.

For histopathological studies the affected pieces of parasitized ceca were fixed in Boun's fluid for 24 hours and further processed by using routine histological techniques [14]. These pieces were processed in paraffin wax for embedding and $6 \mu \mathrm{m}$ thick sections were cut on manual Rotary microtome then stained in (H\&E) heamatoxylene and eosin. Finally stained sections were mounted in Canada balsam. Photomicrographs of the selected sections were taken with help of camera Olympus Dp12.

\section{Results and discussion}

The nematode parasite Heterakis gallinarum has widely host distribution in birds and a little work related to pathology is often reported. In present study one species of nematode parasite was recovered from the cecum of infested birds. The Parasite was identified as Heterakis gallinarum on the basis of structural characters by the help of keys and literature Souls by (1982) and their prevalence was $20 \%$ among recovered helminthes. Free range scavenging system and contaminated food are considered as major contributing factors for infestation of Heterakis gallinarum in poultry [15]. Only one nematode species was recovered from the exotic chickens during wet and dry seasons in scavenging birds and no occurrences of trematode was found [16]. Histopathology of Heterakis gallinarum in common pheasants show high prevalence of necropsies infection with gross lesion, obstruction, thickening and petechial mucosa, bowel obstructions and nodular granulomas in the ceca. Sub mucosal examination confirms chronic inflammation of cecum, hemosiderosis, granulomas, and leiomyomata. The immature $H$. gallinarum was recovered from the muscular and serosal region of intestine. These pathological lesions in birds reveal severe 
sub mucosal damage caused by $H$. gallinarum that results numerous necroses interrelated with cholesterol cleft and neoplastic nodules [17]. In the present histological investigations ceca of noninfected chicken showed normal sub mucosal and serosal region (Figure 1). Ceca also exhibited normal architecture of columnar epithelia contain enterocytes with microvilli and goblet cells, lamina propria mucosae and crypts of lieberkuhn (Figure 2).
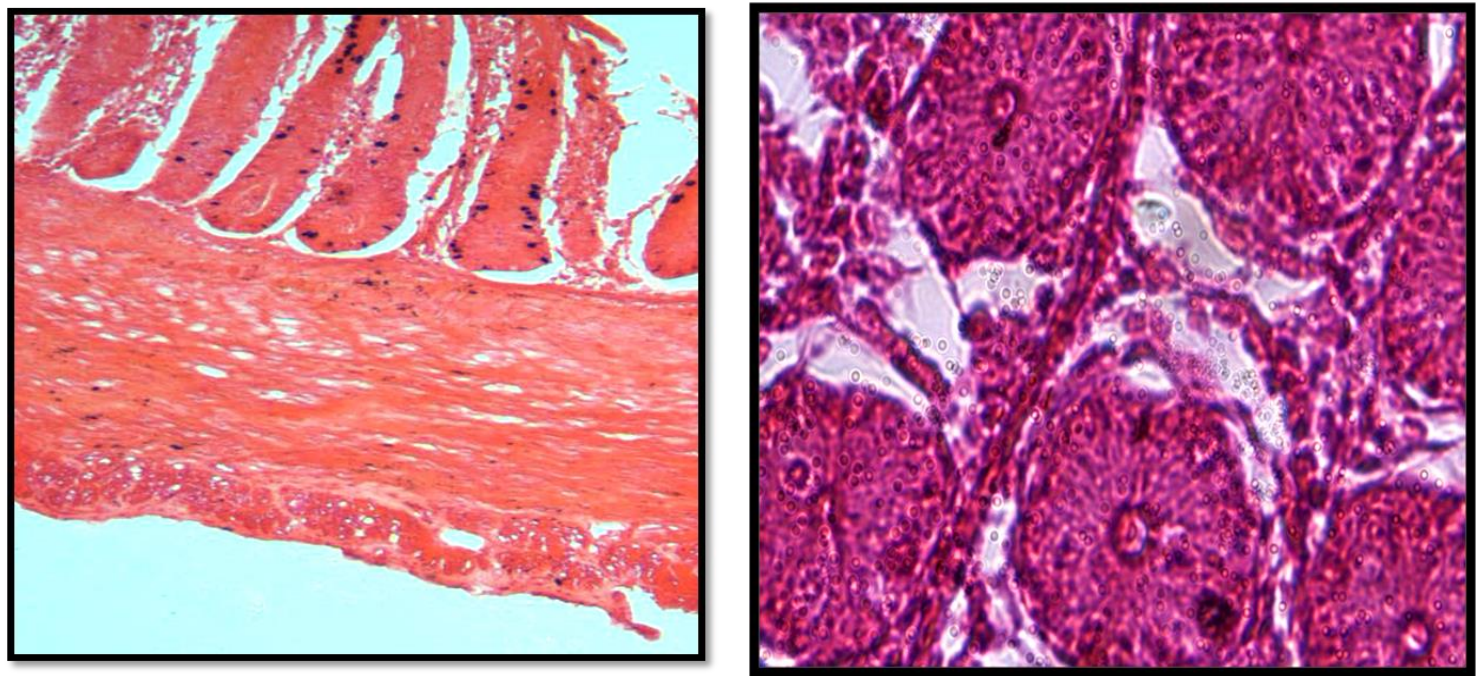

Figure1-2. Section of non-infected ceca of chicken is showing normal intestinal glands and muscular mucosa. Ceca are consisting of simple columnar epithelium, lamina propria and crypts of lieberkuhn with normal structure

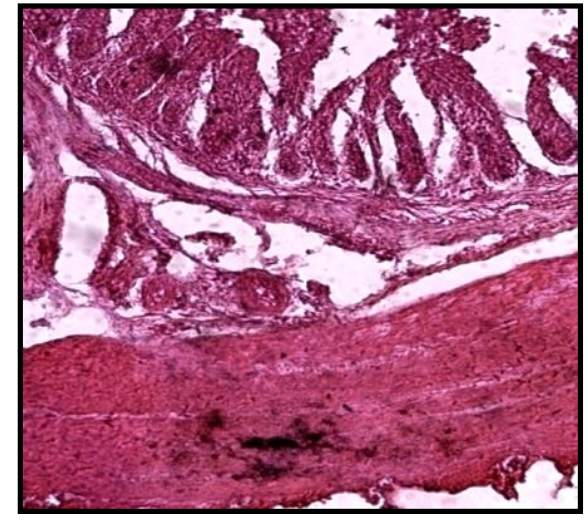

Figure 3. Section of infected ceca of chicken showing intestinal glands which are totally fused and filled with inflammatory cells. Distortion of muscular layer is obvious. Note two arteries with obscure morphology X100

Whereas ceca of infected chicken with Heterakis gallinarum represents fused architecture (Figure 3). Consequently these intestinal glands fused and come out as a cellular mass (Figure 4) and degeneration of intestinal glands, necrosis and infiltrated caecal lamina propria were also observed
(Figure 5). The infiltrated colon lamina proparia present in the intestine of duck infected by Heterakis gallinarum [18]. Nematode parasite cause hemorrhagic enteritis and sinusitis in the intestine therefore sever destruction and deterioration of microvilli observed in duck flocks [19]. 
The Heterakis gallinarum parasites cause inflammation, damage of intestinal glands and muscularis mucosae in pigeons [20]. The findings of present investigations reflect that Heterakis gallinarum exerted alterations in muscular layer along with vacuolation in the ceca of infected birds (Figure 6-7). The occurrence of intestinal infection associated with $H$. gallinarum shows severe inflammatory reaction in cecum $[21,22]$.

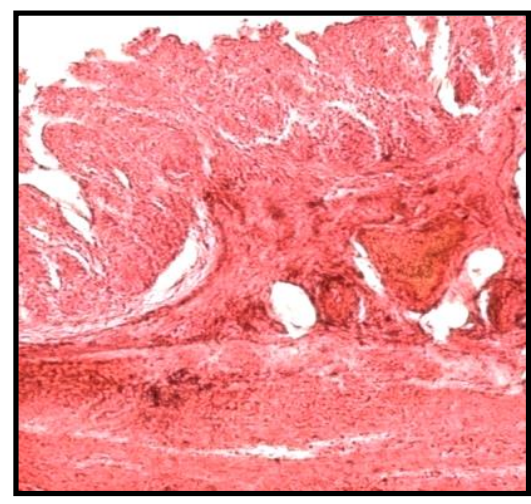

Figure 4. Section of infected ceca of chicken showing fused structure. Only mass of cells are seen $\mathrm{X100}$

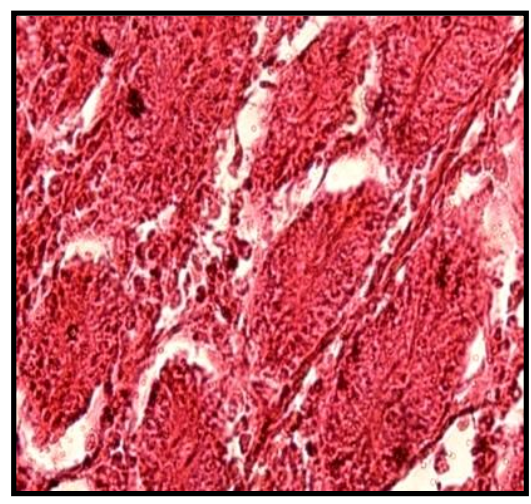

Figure 5. Portion of infected ceca of chicken showing fusion of intestinal glands, destruction of basement membrane and lamina proparia $X 400$

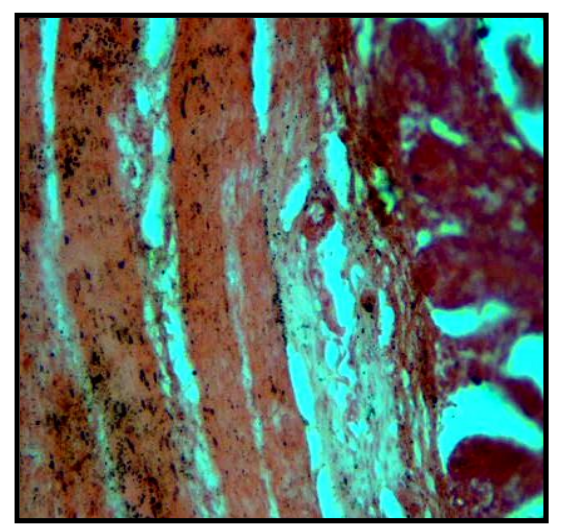

Figure 6. Micrograph of infected ceca showing separation of muscular layer at the base of glands, necrosis of lamina proparia is obvious X200 
Pathological alterations detect tiny white circumscribed nodules measuring $2-3 \mathrm{~mm}$ in the intestinal mucosa in case of $H$. gallinarum infestations [23, 24]. In accordance to previously reported results in birds, findings of present study revealed, narrow, blocked and distorted blood vessels in muscular layer of ceca (Figure 8). Histopathological results of present experimental study on Heterakis gallinarum in the ceca of infected birds reveal widerange muscular alterations and damage affecting entire structure of gastro intestine. Hence, proper knowledge and advanced poultry farming practices are recommended to reduce the nematode parasitism in local birds to avoid further economical losses.

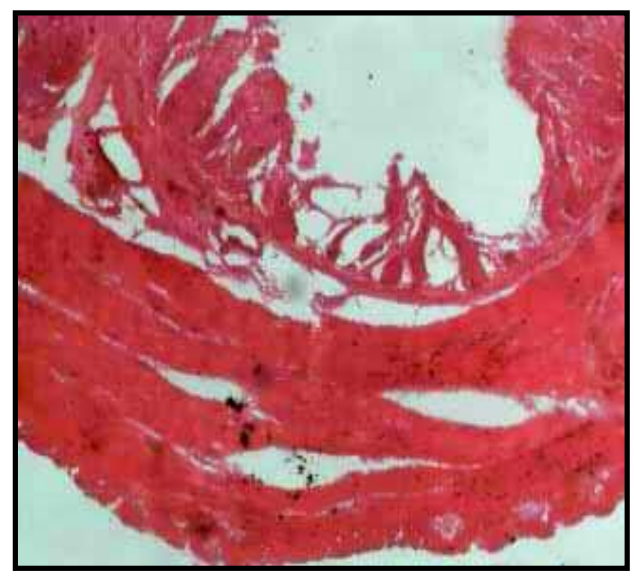

Figure 7. Section of infected ceca at low magnification showing separation and distortion of muscular layer X400

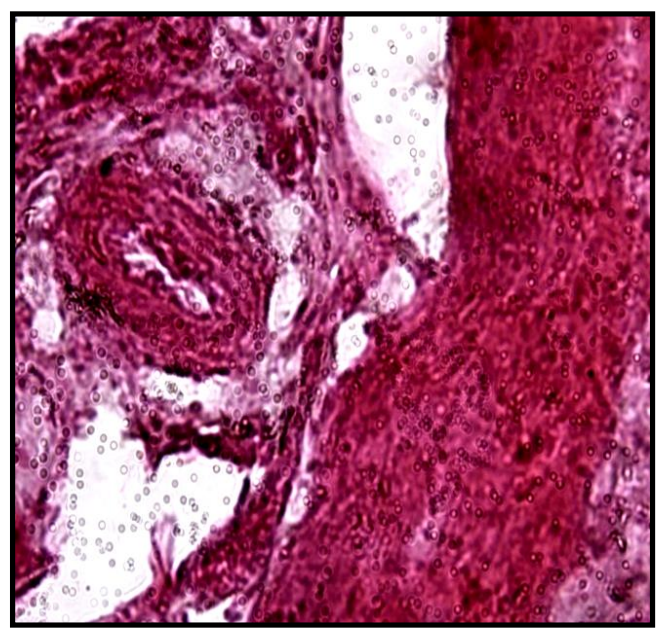

Figure 8. Portion of muscular layer of infected ceca showing an artery which is totally blocked X400

\section{Authors' contribution}

Conceived and designed the experiments: $\mathrm{Z}$ Butt, Performed the experiments: Z Butt, Analyzed the data: Z Butt, SA Memon \& AA Shaikh, Contributed reagents/ materials/ analysis tools: Z Butt, SA Memon \& AA Shaikh, Wrote the paper: Z Butt \& SA Memon. 


\section{References}

1. Zubeda B (2012). Pathological changes in the intestine of chicken naturally infected with helminth parasites. Hyderabad Sindh, Pakistan. M. Phil. Thesis Deptt. of Zoology, Uni of Sindh, Jamshoro, Pakistan.

2. Samat MT (2009). "The history of poultry" The history of food, Ch 11 . revised ed, pp. 306.

3. Asefaw $\mathrm{HG}$, Gorm $\mathrm{P}$, Anderson $\mathrm{P} \&$ Uswege M (2000). Smallholder poultry production in Eritrea. Possibilties for smallholder poultry projects in East and South Africa, proceeding workshop. Morgoro Tanzania. 23-27

4. Ashenafi H \& Eshetu Y (2004). Study on gastrointestinal helminths of local chickens in central Ethiopia. Rev Med Vet 155(10): 504-507.

5. Eshetu Y, Mulualem E, Ibrahim $\mathrm{H}$, Berhanu A \& Averra (2001) Study of gastro-intestinal helminths of scavenging chickens in four rural districts of Amhara region. Ethiopia Rev Sci Technol 20(3): 791-796.

6. Jordan FTM \& Pattison M (1996). Poultry diseases, 4th edition, pp 283-286.

7. Mukaratirwa S \& Khumalo MP (2010). Prevalence of helminth parasites in freerange chickens from selected rural communities in Kwazulu-Natal province of South Africa Journal of south African Veterinary Association 81(2):97-101

8. Dube S, Zindi P, Mbanga J \& Dube C (2010). A study of scavenging poultry gastrointestinal and ecto-parasites in rural areas of Matebeleland province, Zimbabwe. Int J Poult Sci 9 (9): 911915.

9. Puttalakshmamma GC, Ananda KJ, Prathiush PR, Mamatha GS \& Rao S (2008). Prevalence of gastrointestinal parasites of poultry in and around Banglore. Vet World 1(7): 201-202.
10. Sayyed RS, Phulan MS, Bhatti WM, Pardeshi M \& Ali S (2000). Incidence of nematode parasites in commercial layers in sawat. Pakistan Vet $J 20$ (2):107-108.

11. Shah AH, Anwar AH, Khan MN, Iqbal Z \& Qudoos A (1999). Comparative studies on the prevalence of cestode parasites in indigenous and exotic layers at Faisalabad. Int J Boil 1(4): 277-279.

12. Zahida T, Fariha A \& Masood A (1999). Prevalence of cestode parasites of domesic fowl (Gallus gallus domesticus) Pakistan Vet J 19 (3): 1999.

13. Dharejo AM (2006). Trematode parasites of birds of different feeding habits of Hyderabad District, Hyderabad, Sindh, Pakistan. PhD thesis, Faculty of Natural Sciences, University of Sindh, Jamshoro, Pakistan.

14. Bilqees FM \& Fatima H (1993). Microtomy and Histopathology Techniques. MAHQ Biol Res Cent Univ of Karachi pp. 1-16.

15. Eshetu Y, Mulualem E, Ibrahim H, Berhanu A \& Averra (2001). Study of gastro-intestinal helminths of scavenging chickens in four rural districts of Amhara region. Ethiopia Rev Sci Technol 20 (3): 791-796.

16. Permin A, Hagwishu AA, Kassuku P, Nansen M, Prisgaard F \& Gibbons L (1997). A Cross-sectional study of helminths in rural scavenging poultry in tanzana in relation to season and climate. $J$ Helminthol 71 (3):233-240.

17. Menezes RC, Tortelly RDC, Gomes RM, Pinto (2003). Nodular Typhlitis Associated with the Nematodes Heterakis gallinarum and Heterakis isolonche in Pheasants: frequency and pathology with evidence of neoplasia. Mem Inst Oswaldo Cruz, Rio de Janeiro 98(8): 1011-1016.

18. Yousuf MA, Das PM \& Banowary B (2009). Gastro- intestinal helminths of ducks: Some Epidemiologic and 
pathologic aspects. J. Bangladesh Agri Univ 7(1): 91-97.

19. Forester DJ, Kinsella JM, Mertins JW, Price RD \& Turnbull RE (1994). Parasitic helminthes and arthropods of whistilingducks in Southern Florida. J. Helminthol Soci Washinton 61(1): 84-88.

20. Adang KL, Abdu PA, Ajanusi JO, Oniye SJ \& Ezealor AU (2010) Effects of Ascarida galli infection on body weight, packed cell volume, hemoglobin level and total plasma protein of experimentally infected domestic pigeons (C. L. Domestic) In Zaria, Nigeria. Global Journal of Medical Research 10(2): 6-11.

21. Brener B, Tortelly R, Menezes RC, Muniza-Pereira Lc \& Pinto RM (2006). Prevalence and pathology of the nematode Heterakis gallinarum, the trematode Paratanaisia bargia, and protozoan Histomonas meleagridis in turkey, Meleagris gallopavo.Mem Inst Oswaldo Curz Rio de Janeiro 101(6): 677-681.

22. Hange RR, Raote YV \& Jayraw AK (2007). Prevalence of helminth parasites in desi fowl (Gallus gallus domesticus) at Parbhani. Journal of Parasitic Diseases 31(1): 61-64.

23. Rabbi MA, Islam A, Majumder $\mathrm{S}$, Rahman MH (2006). Gastrointestinal helminthes infection in different types of poultry. Bangl J Vet Med 4 (1): 13-18.

24. Phiri IK, Phiri AM, Ziela M, Chota A, Masuku M \& Monrad J (2007). Prevalence and distribution of gastrointestinal helminthes and their effects on weight gain in free-range chickens in Central Zambia. Trop Animal Health Prod 39 (4):309-315. 